\title{
Clinical application of a single-operator direct visualization system improves the diagnostic and therapeutic yield of endoscopic retrograde cholangiopancreatography
}

\author{
Turki AlAmeel MD FRCPC, Vincent Bain MD FRCPC, Gurpal Sandha MBBS FRCPC
}

T AlAmeel, V Bain, G Sandha. Clinical application of a single-operator direct visualization system improves the diagnostic and therapeutic yield of endoscopic retrograde cholangiopancreatography. Can J Gastroenterol 2013;27(1): 15-19.

BACKGROUND: Single-operator cholangioscopy enables direct diagnostic visualization and therapeutic intervention in the biliary tree. There is increasing evidence of its clinical utility in the assessment of biliary strictures and treatment of difficult stones.

OBJECTIVE: To describe the first reported Canadian experience with managing biliary disease using single-operator cholangioscopy.

METHODS: The present study was a retrospective analysis of data collected from all sequential patients undergoing single-operator cholangioscopy for assessment of biliary strictures and treatment of biliary stones. The main outcome measures were the ability to make an overall diagnosis of stricture (based on visual appearances and tissue histology), and to fragment and extract biliary stones.

RESULTS: Thirty patients ( 17 women), mean age 66 years (range 41 to 89 years) underwent single-operator cholangioscopy. In biliary strictures (20 patients), overall accuracy for visual and tissue diagnosis was $84 \%$ and $81 \%$, respectively. Successful electrohydraulic lithotripsy with stone clearance was achieved in $90 \%$ of the 10 patients who failed previous conventional therapy. The mean $( \pm \mathrm{SD})$ procedure time was $61 \pm 21 \mathrm{~min}$ (range $20 \mathrm{~min}$ to $119 \mathrm{~min}$ ). One patient developed mild postendoscopic retrograde cholangioscopy pancreatitis.

CONCLUSION: The results of this experience reaffirms the clinical utility and safety of single-operator cholangioscopy for the management of biliary pathology. Further improvements can be achieved with increasing operator experience and refinements in optical technology.

Key Words: Biopsy; Cholangioscopy; Lithotripsy; SpyGlass; Stone; Stricture

The assessment of biliary strictures remains a significant challenge. Malignant strictures (cholangiocarcinoma) often grow longitudinally rather than in a radial fashion and, thus, large tumour masses are often absent on modalities such as abdominal ultrasound, computed tomography and magnetic resonance imaging (1). Inflammatory strictures (eg, primary sclerosing cholangitis [PSC]), especially with their potential for developing malignancy, are also equally difficult to accurately diagnose and follow. Current clinical practices, such as biliary brush cytology and endoscopic retrograde cholangiopancreatography (ERCP)-directed biopsy acquisition, have a less than optimal sensitivity of $33 \%$ to $58 \%(2-4)$. False-negative results can delay life-saving interventions (5). On the other hand, false positives can result in unnecessary surgical intervention, thereby increasing morbidity and health care costs. The need for improved efforts to obtain accurate and directed tissue diagnosis cannot be overemphasized.

To enable direct visualization and have the ability to perform biopsies of lesions within the bile duct, flexible cholangioscopes were developed in the 1990s and have been used in a procedure often

\section{L'application clinique d'un système de visualisation directe par un seul opérateur améliore le rendement diagnostique et thérapeutique de la cholangiopancréatographie endoscopique rétrograde}

HISTORIQUE : La cholangioscopie par un seul opérateur permet une visualisation diagnostique immédiate et une intervention thérapeutique directement dans l'arbre biliaire. Les données probantes s'accumulent pour en étayer l'utilité clinique dans l'évaluation des rétrécissements biliaires et le traitement des calculs complexes.

OBJECTIF : Décrire la première expérience canadienne déclarée sur la prise en charge d'une maladie biliaire à l'aide d'une cholangioscopie par un seul opérateur.

MÉTHODOLOGIE : La présente étude était une analyse rétrospective des données colligées auprès de tous les patients séquentiels qui avaient subi une cholangioscopie par un seul opérateur pour évaluer les rétrécissements biliaires et le traitement des calculs biliaires. Les principales mesures d'issue étaient la capacité de poser un diagnostic global de rétrécissement (d'après l'apparence visuelle et l'histologie tissulaire) et de fragmenter et extraire les calculs biliaires.

RÉSULTATS : Trente patients (17 femmes), d'un âge moyen de 66 ans (plage de 41 à 89 ans) ont subi une cholangioscopie par un seul opérateur. En cas de rétrécissement biliaire (20 patients), la précision globale du diagnostic visuel et tissulaire s'élevait à $84 \%$ et à $81 \%$, respectivement. On a observé une lithotripsie électrohydraulique avec clairance des calculs chez $90 \%$ des dix patients dont la thérapie classique avait échoué auparavant. L'intervention avait une durée moyenne ( \pm ÉT) de $61 \pm 21$ min (plage de 20 minutes à 119 minutes). Un patient a présenté une pancréatite cholangioscopique rétrograde bénigne après l'endoscopie.

CONCLUSION : Les résultats de cette expérience réitèrent l'utilité et l'innocuité cliniques d'une cholangioscopie par un seul opérateur pour prendre en charge une pathologie biliaire. Les améliorations peuvent être directement proportionnelles à l'expérience de l'opérateur et au perfectionnement de la technologie optique.

referred to as 'mother-baby' cholangioscopy (6). The procedure requires two experienced endoscopists, one to work the 'mother' duodenoscope and the other to operate the 'baby' cholangioscope. The latter is introduced through the working channel of the 'mother' scope. This has proven to be a cumbersome procedure and has not achieved widespread use. In addition, the 'baby' cholangioscope only has two-way tip deflection capability, limiting its manoeuvreability, and is subject to increased repair costs because of its fragility.

The 'SpyGlass' (Boston Scientific, USA) cholangioscopy system is a relatively recent advance that enables one endoscopist to manoeuvre both the duodenoscope and the cholangioscope, enabling direct visualization of the bile duct. Studies have recently documented its clinical usefulness not only for the diagnosis of strictures (with biopsy) but also for therapeutic (with electrohydraulic lithotripsy [EHL] or laser lithotripsy) intervention of biliary stones refractory to conventional treatment (7-11).

The objective of the present study was to describe our experience with SpyGlass cholangioscopy in managing biliary disease.

Division of Gastroenterology, University of Alberta Hospital, Edmonton, Alberta

Correspondence: Dr Gurpal Sandha, Division of Gastroenterology, University of Alberta Hospital, Zeidler Ledcor Centre, 130 University Campus,

Edmonton, Alberta T6G 2X8. Telephone 780-492-8170, fax 780-492-1699, e-mail gurpal.sandha@ualberta.ca

Received for publication May 23, 2012. Accepted June 4, 2012 


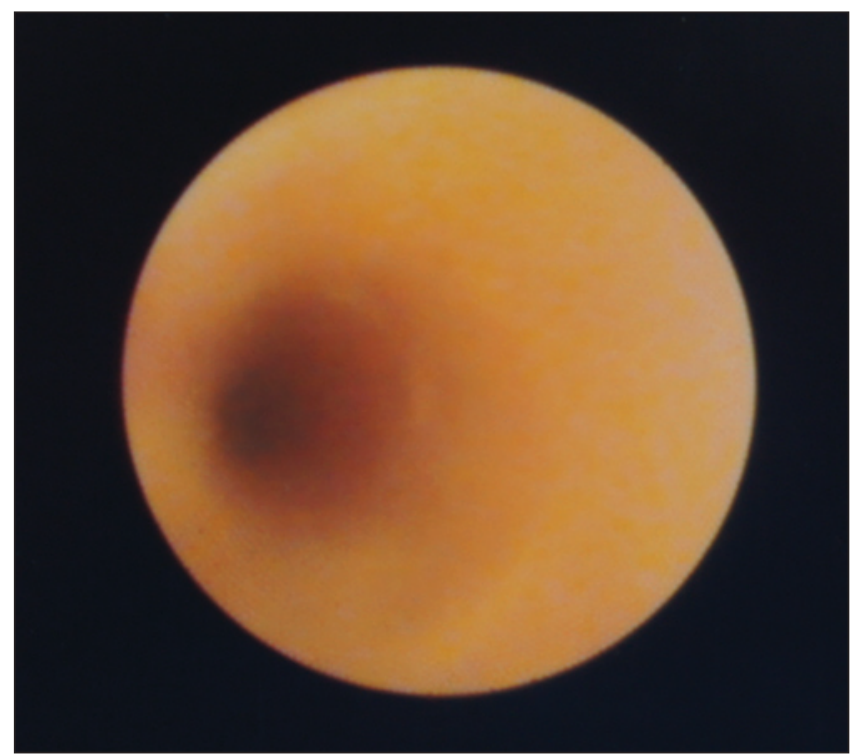

Figure 1) Common bile duct stricture in a patient with primary sclerosing cholangitis exhibiting smooth cicatrization without the presence of any mass lesion

\section{METHODS}

The present analysis was an observational study evaluating data from all patients who underwent diagnostic and/or therapeutic SpyGlass cholangioscopy at the University of Alberta Hospital in Edmonton, Alberta. All procedures were performed by two experienced biliary endoscopists (VB and GS), with individual ERCP experience of $>12$ years, having performed $>2000$ procedures each.

The SpyGlass cholangioscopy system is a single-operator, direct visualization system that is introduced via the working channel of a standard duodenoscope (Olympus TJF180 therapeutic duodenoscope, Olympus America Inc, USA). The SpyGlass system consists of a disposable SpyScope access and delivery catheter, a $10 \mathrm{Fr}$ catheter with four-way tip deflection capability, channels for accommodating optical and accessory devices and two channels for saline irrigation, the reusable SpyGlass direct visualization optical probe for visual examination of the pancreaticobiliary ducts and the disposable SpyBite biopsy forceps for tissue acquisition (7). The generator and probes for EHL and laser lithotripsy are additional accessories acquired separately (see below).

\section{Outcomes and procedure}

The data were analyzed using an intent-to-diagnose approach for the assessment of biliary strictures and an intent-to-treat approach for biliary stones.

Biliary strictures: Using the intent-to-diagnose approach for biliary strictures, the ability of SpyGlass to aid in making a visual diagnosis and then to biopsy any mucosal abnormality identified using the SpyBite forceps was assessed. The inability to make a visual diagnosis or to obtain biopsies, where indicated, was considered a failure of the procedure. The visual diagnosis was categorized as a malignant stricture (ie, cholangiocarcinoma) or a stricture resulting either from a benign, inflammatory process (ie, PSC) or from extrinsic compression (eg, carcinoma of the gallbladder, pancreatic adenocarcinoma or autoimmune pancreatitis).

The visual diagnosis with SpyBite tissue histology was individually correlated with surgical histology or clinical follow-up and SpyBite biopsy diagnosis with either surgical histology, where available, or clinical follow-up. The accuracy of both the visual ability of SpyGlass cholangioscopy to establish a diagnosis as well as the ability of SpyBite biopsies to confirm histology has been reported by previous investigators (7-9).
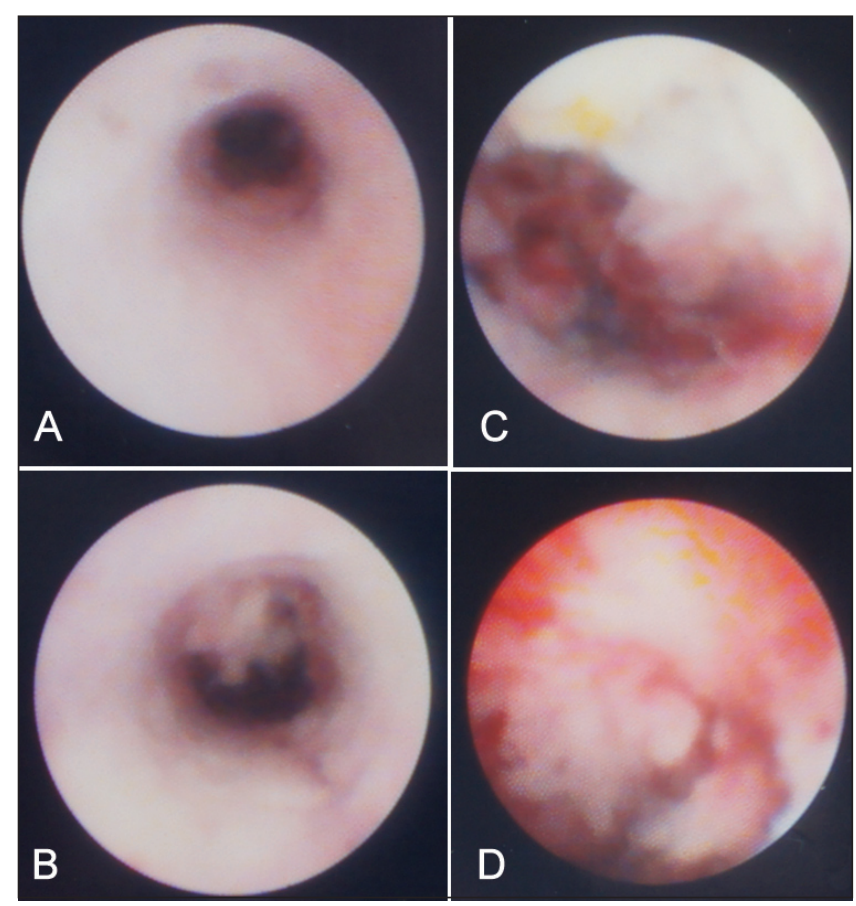

Figure 2) A series of images from a patient with primary sclerosing cholangitis with a mass lesion. A Normal distal bile duct. B The beginning of a mural-based mass. C and D The mass is clearly visible and was biopsied with SpyBite forceps (Boston Scientific, USA)

An attempt was made to make an overall SpyGlass diagnosis in all patients. This was the final impression of the endoscopist and was based on information obtained from both the visual and tissue diagnosis. This overall diagnosis was made based on the most concerning interpretation. For example, if a stricture was considered to be malignant by visual diagnosis and the biopsy was reported benign and/or inflammatory, a diagnosis of a malignant stricture was entertained as the overall SpyGlass diagnosis.

Because the present study was observational in nature and reports the institution's early experience with SpyGlass cholangioscopy, a follow-up time period was not defined a priori but simply reported at the time of preparing the manuscript.

Figure 1 is an example of PSC in which only a visual diagnosis was made. The mass lesion shown in Figure 2 was found in a patient with PSC who underwent SpyBite biopsy. Figure 3 is an example of an apple-core lesion that appeared malignant on visual inspection and then underwent SpyBite biopsy.

Biliary stones: For biliary stone lithotripsy, an EHL pulse generator (Northgate Technologies Inc, USA) was used. The intent-to-treat approach involved an attempt to visualize and fracture the targeted biliary stone(s) and eventually extract all fragments with the aim of bile duct clearance. The settings used on the pulse generator were as follows: power $30 \mathrm{~W}$ to $50 \mathrm{~W}$, with a maximum of up to $100 \mathrm{~W}$, if needed; and frequency 10 pulses/s to 30 pulses/s for 2 s. EHL is performed most effectively while irrigating with normal saline. After stone fragmentation, the need for additional intervention to aid in stone extraction (eg, balloon dilation of the sphincter and/or the use of balloon and/or basket extraction catheters) was left to the discretion of the endoscopist. If repeat ERCP was needed for EHL, this was considered in the analysis as a separate procedure, but if the repeat ERCP was simply to extract stones without the need for SpyGlass and/or EHL, these repeat procedures were not included in the final analysis. Inability to fracture the stone(s) with EHL was considered a failure of SpyGlass cholangioscopy. Figure 4 presents the various steps in the process of EHL with stone fracture and extraction of fragments from the bile duct. 


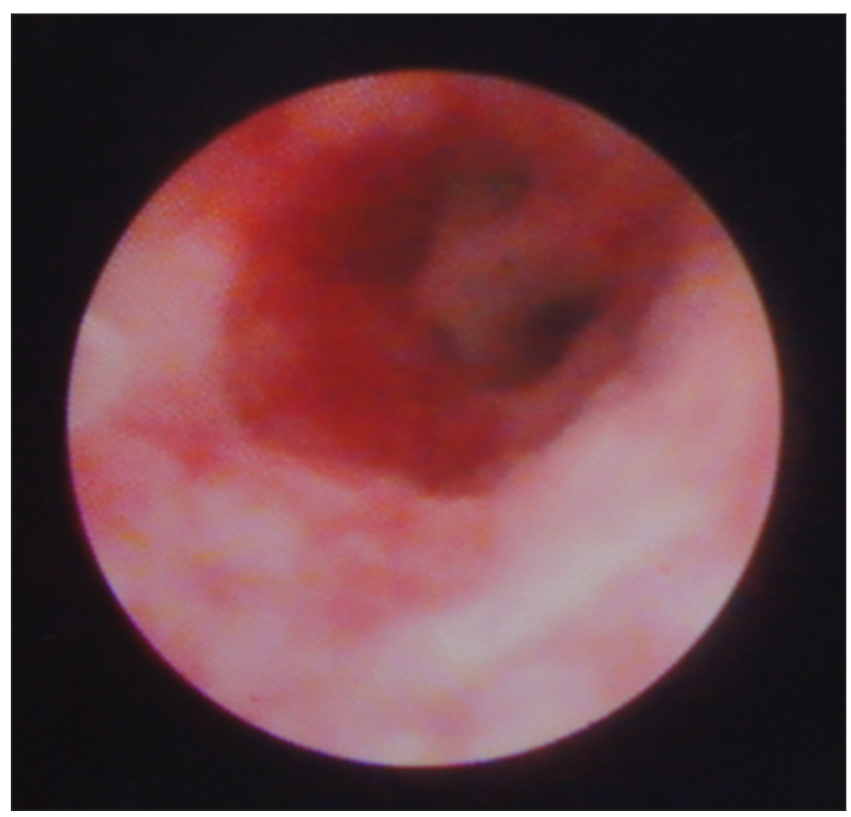

Figure 3) Cholangioscopic view of a malignant-appearing stricture exhibiting an 'apple-core' lesion

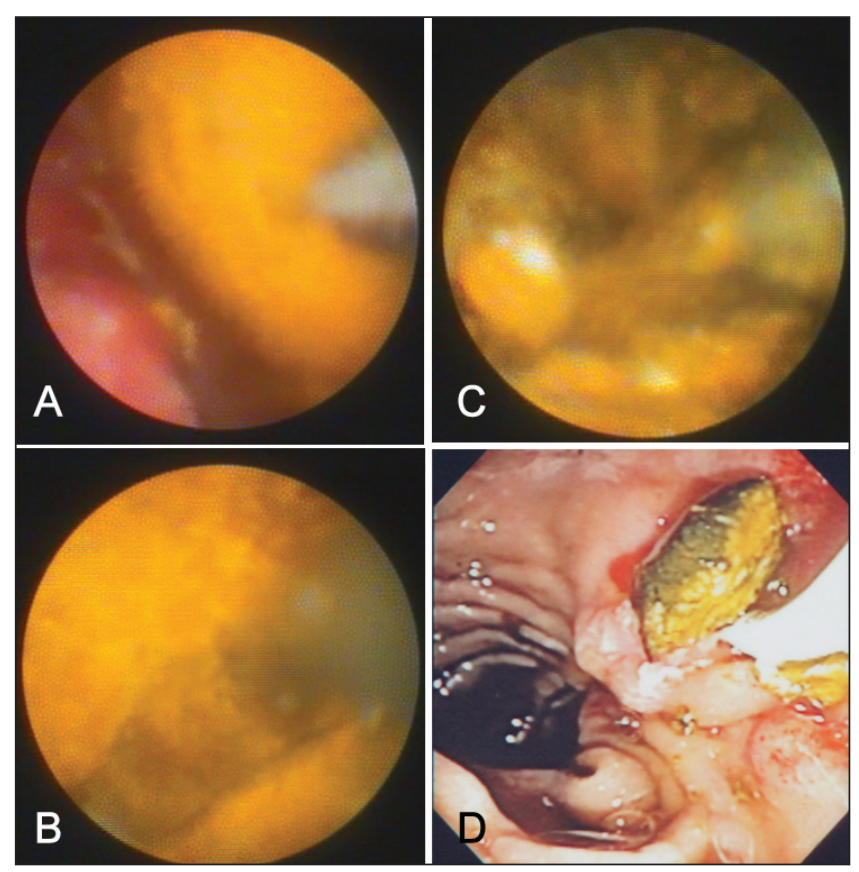

Figure 4) These images reveal the steps during electrohydraulic lithotripsy (EHL) of a large biliary stone. A Cholangioscopic view of the stone with EHL probe visible. B Initial fracture site in the stone. C Fragmentation of the stone with sequential EHL applications. D Extraction of fragments with balloon-extraction catheter

All patients who underwent SpyGlass cholangioscopy underwent at least one previous ERCP with sphincterotomy and/or stent placement, either by one of the two study endoscopists or by the referring endoscopist. The SpyGlass procedures were planned electively and not performed on an ad hoc basis, in part, because the infection control policy at the institution requires cleansing and disinfection of the reusable SpyGlass fibreoptic probe at least $24 \mathrm{~h}$ before the procedure. All cholangioscopy procedures were performed under general anesthesia because prolonged procedures were anticipated and operators preferred not to have suboptimal sedation become a potential explanation for inadequate procedure performance.
TABLE 1

Baseline patient demographics with clinical characteristics and procedure outcome

\begin{tabular}{|c|c|}
\hline Patients, $\mathrm{n}$ & 30 \\
\hline Age, years, mean (range) & $66(41-89)$ \\
\hline Sex, male/female, $\mathrm{n} / \mathrm{n}$ & $13 / 17$ \\
\hline \multicolumn{2}{|l|}{ Biliary stricture $(n=20)$} \\
\hline \multicolumn{2}{|l|}{ Anatomical location, $\mathrm{n}$} \\
\hline Distal one-third of bile duct & 5 \\
\hline Proximal two-thirds of bile duct & 15 \\
\hline \multicolumn{2}{|l|}{ SpyGlass $^{\star}$ visual diagnosis ${ }^{\dagger}$ (see Table 2 ) } \\
\hline Achieved, $\mathrm{n}$ & 19 \\
\hline Sensitivity, \% & 83 \\
\hline Specificity, \% & 84 \\
\hline \multicolumn{2}{|l|}{ SpyBite $^{\star}$ tissue diagnosis ${ }^{\ddagger}$ (see Table 3 ) } \\
\hline Achieved, $\mathrm{n}$ & 16 \\
\hline Sensitivity, \% & 40 \\
\hline Specificity, $\%$ & 100 \\
\hline \multicolumn{2}{|l|}{ Overall SpyGlass diagnosis (see Table 4) } \\
\hline Achieved, $\mathrm{n}$ & 20 \\
\hline Sensitivity, \% & 86 \\
\hline Specificity, \% & 85 \\
\hline \multicolumn{2}{|l|}{ Biliary stones $(n=10)^{\S}$} \\
\hline \multicolumn{2}{|l|}{ Indication, $\mathrm{n}$} \\
\hline Multiple/large/faceted stone(s) & 3 \\
\hline Impacted stone(s) & 3 \\
\hline Stone(s) above stricture & 2 \\
\hline Electrohydraulic lithotripsy & 8 \\
\hline \multicolumn{2}{|l|}{ Stone extraction, n (>1 may apply) } \\
\hline Balloon extraction & 8 \\
\hline Basket extraction & 2 \\
\hline Dilation assisted stone extraction & 2 \\
\hline Duration of procedure, min, mean \pm SD (range) & $61 \pm 20(20-119)$ \\
\hline
\end{tabular}

${ }^{*}$ Boston Scientific, USA; 'Visualization could not be achieved in one patient; ${ }^{\ddagger}$ No lesion identified in four patients; therefore, no biopsy attempted; ${ }^{8}$ One patient had no stone identified and, in another patient, there was difficulty visualizing the stone. Electrohydraulic lithotripsy was not performed in these two patients

There was no funding available for the present study and it was approved by the local institutional health research ethics board.

\section{Statistical analysis}

Descriptive statistics included mean, SD and range. Statistical analysis of the data with calculation of sensitivity, specificity, positive predictive value (PPV) and negative predictive value (NPV) was performed using two-way contingency table analysis.

\section{RESULTS}

In the first 12 months (starting April 2011), 30 patients (17 women) with a mean age of 66 years (range 41 to 89 years) underwent ERCP with SpyGlass cholangioscopy. The mean $( \pm \mathrm{SD})$ procedure time for the entire cohort was $61 \pm 20 \mathrm{~min}$ (range $20 \mathrm{~min}$ to $119 \mathrm{~min}$ ). Table 1 summarizes the patient demographics and procedure indications, along with outcomes of intervention and corroborating information where available. The data were analyzed on an intention-to-diagnose and/or intent-to-treat basis.

The two main indications for SpyGlass cholangioscopy were assessment of undiagnosed biliary strictures and EHL of biliary stones that were refractory to previous attempts with conventional modalities. The analysis of the results for these indications will be discussed separately. 


\section{TABLE 2}

$2 \times 2$ table describing the relationship between a visual diagnosis made during SpyGlass* cholangioscopy and verified against tissue diagnosis (SpyBite* and/or surgical histology, where available) and clinical follow-up

\begin{tabular}{lccc}
\hline & \multicolumn{2}{c}{$\begin{array}{c}\text { Tissue diagnosis (SpyBite and/or surgical } \\
\text { histology) and clinical follow-up }\end{array}$} \\
\cline { 2 - 4 } & Malignant & Benign/extrinsic & Total \\
\hline SpyGlass visual diagnosis & 5 & 2 & 7 \\
Malignant & 1 & 11 & 12 \\
Benign/extrinsic & 6 & 13 & 19 \\
Total & & & \\
\hline
\end{tabular}

*Boston Scientific, USA

TABLE 3

$2 \times 2$ table describing the relationship between SpyBite* tissue diagnosis verified against surgical histology, where available, and clinical follow-up

\begin{tabular}{lccc}
\hline & \multicolumn{3}{c}{ Surgical histology and clinical follow-up } \\
\cline { 2 - 4 } & Malignant & Benign/extrinsic & Total \\
\hline SpyBite tissue diagnosis & 2 & 0 & 2 \\
Malignant & 3 & 11 & 14 \\
Benign/extrinsic & 5 & 11 & 16 \\
Total & &
\end{tabular}

*Boston Scientific, USA

\section{Biliary stricture assessment}

Of the 30 patients, $20(67 \%)$ with a mean age of 64 years (range 41 to 82 years) were referred for assessment of biliary strictures. There were 12 women $(60 \%)$. The location of stricture was in the distal one-third of the bile duct in five patients and in the proximal two-thirds in the remaining 15 patients. The mean procedure time was $55 \pm 16 \mathrm{~min}$ (range $20 \mathrm{~min}$ to $87 \mathrm{~min}$ ). The mean follow-up period was five months (range two to 12 months). Only four patients had corroborating surgical histology available. Three other patients died within the follow-up period, presumably of malignant disease, although confirmation by autopsy was not available.

SpyGlass visual diagnosis: The overall success of SpyGlass cholangioscopy in identifying the biliary stricture and making a visual diagnosis with respect to location, length and surface characteristics was $95 \%$ (19 of 20 patients). A distal stricture could not be visualized in one patient. The sensitivity (83\%), specificity (84\%), PPV (71\%), NPV $(91 \%)$ and overall accuracy $(84 \%)$ of the ability of SpyGlass to make a visual diagnosis are shown in Table 2.

SpyBite tissue diagnosis: Of the 20 patients, SpyBite biopsies were attempted and obtained in 16 patients. Biopsies were not performed in four patients in whom no obvious mucosal abnormality was apparent. The sensitivity (40\%), specificity (100\%), PPV (100\%), NPV (78\%) and overall accuracy (81\%) of SpyBite biopsies to confirm the visual diagnosis are shown in Table 3.

Overall SpyGlass diagnosis: All 20 patients who underwent SpyGlass cholangioscopy for biliary strictures were included. The sensitivity (86\%), specificity (85\%), PPV (75\%), NPV (92\%) and overall accuracy $(85 \%)$ of the ability of SpyGlass cholangioscopy to make an overall diagnosis are shown in Table 4.

\section{Biliary stone management}

Ten patients were referred for EHL for difficult stones. These patients were generally older (mean age 72 years, range 52 to 89 years) and sex was more evenly distributed (five females [50\%]) than the biliary stricture cohort. Furthermore, the mean procedure time was longer for this group ( $72 \pm 25 \mathrm{~min}$, range $36 \mathrm{~min}$ to $119 \mathrm{~min}$ ). The indications for EHL in these patients were impacted stones, multiple large and faceted stones, and stones situated above a biliary stricture.

The overall success with an intent-to-treat approach was $90 \%$ (nine of 10 patients). EHL was attempted and successful in eight of
TABLE 4

$2 \times 2$ table describing the overall SpyGlass* impression (SpyGlass visual diagnosis and SpyBite* tissue diagnosis) verified against surgical histology, where available, and/or clinical follow-up

\begin{tabular}{lccc}
\hline & \multicolumn{3}{c}{ Surgical histology and/or clinical follow-up } \\
\cline { 2 - 4 } & Malignant & Benign/extrinsic & Total \\
\hline Overall SpyGlass diagnosis & & & \\
Malignant & 6 & 2 & 8 \\
Benign/extrinsic & 1 & 11 & 12 \\
Total & 7 & 13 & 20 \\
\hline
\end{tabular}

*Boston Scientific, USA

nine patients (89\%), and eventual clearance of the duct was achieved in all patients. No patient required more than one SpyGlass or EHL session, although one patient with multiple large stones underwent a repeat ERCP for extraction of stone fragments and duct clearance. In one patient referred for a reportedly 'large' stone, a stone could not be visualized despite cholangiography and cholangioscopy. No subsequent intervention has been performed in this patient in 11 months of follow-up. One patient had a $1 \mathrm{~cm}$ stone situated distally in a dilated bile duct. Adequate visualization was never achieved and, because EHL could not be performed, this was considered to be a failure in the intent-to-treat analysis. The stone was removed during the same procedure after balloon dilation of the sphincter and may not have initially been a good indication for SpyGlass.

\section{Complications}

There has been no major complication associated with SpyGlass cholangioscopy in our experience. One patient developed post-ERCP pancreatitis and recovered well with conservative treatment. One patient with cholangiocarcinoma developed an altered level of consciousness and acute urinary retention $24 \mathrm{~h}$ after the procedure and died three days later. An autopsy was not performed and it remains unclear whether the events were related to the SpyGlass procedure.

\section{DISCUSSION}

Evaluation of undetermined biliary strictures remains one of the most challenging tasks in pancreaticobiliary endoscopy. Conventional methods of investigation, including cross-sectional abdominal imaging, are poor at accurately defining benign and/or malignant lesions of the bile duct. Attempts at obtaining tissue for diagnosis by ERCP with brush cytology and/or ERCP-directed forceps biopsies within the bile duct have not yielded consistent and widely applicable results (2-4). Even the initial promise of endoscopic ultrasound-guided fine-needle aspiration has not translated into widespread use despite favourable results with respect to sensitivity and specificity (12-14).

Direct intraductal visualization of biliary pathology has long been recognized as the best way to evaluate strictures. 'Mother-baby' (also known as 'mother-daughter') biliary endoscopy has been in clinical use for many years (6). However, this procedure also has not seen widespread acceptance, in part, because of the need for two endoscopists. To overcome this particular disadvantage, the SpyGlass single-operator direct visualization system was devised and first clinically tested in 2007 by Chen and Pleskow (7). Since then, various groups have reported their initial experience and success, although only a handful of these studies have collected data in a prospective manner $(8,10)$.

In these initial years of investigation with SpyGlass, several outcome measures have been evaluated. One of these is procedural success, which has been reported by most investigators to be significantly greater than $90 \%(7-11)$. The criteria to diagnose strictures have focused not only on the ability of SpyGlass cholangioscopy to identify the stricture and make a visual diagnosis (sensitivity and specificity ranging between $71 \%$ and $95 \%$, and $79 \%$ and $100 \%$, respectively) but also on the ability of SpyBite forceps biopsies to confirm the initial visual diagnosis (sensitivity and specificity ranging between $49 \%$ and $82 \%$, and $82 \%$ and $98 \%$, respectively) $(7-11)$. Our results are also 
consistent with these published data. Furthermore, the accuracy of SpyGlass in being able to make an overall diagnosis is $85 \%$. This is certainly a significant improvement from the existing standard of care, which includes bile duct brushings and, less often, attempts with ERCP-guided biopsy.

One of the limitations with analyses relating to biliary strictures with SpyGlass cholangioscopy is the consistent lack of a corroborating 'gold standard' for verification of the diagnosis. It is easy to compare SpyGlass intervention (visual and/or biopsy results) against surgical histology, where available; however, as is more common, a vast majority of these patients are deemed inoperable candidates. This leaves investigators to assume the presence of malignancy based on patient survival rather than actual histology. The sensitivity of SpyBite tissue diagnosis in our study (40\%) was less than optimal, and may be explained by the relatively low number of cases and also by the fact that these data are the result of our initial experience with SpyGlass cholangioscopy. We believe that this is likely to improve with increasing experience. Our initial results are comparable with the early experience of other investigators who have had a similarly low sensitivity of SpyBite tissue diagnosis as reported in a recent multicentre registry (9). Moreover, in benign strictures of the bile duct, such as PSC, similar corroborating histology is usually unavailable. Prolonged survival, usually $>6$ months, is assumed to indicate benign disease. This lack of a comparative 'gold standard' is one of the limitations of our study, as it has been for previous investigators.

The published results of intention-to-treat analyses of stone fragmentation and extraction using SpyGlass cholangioscopy are even better, with reported success rates of $92 \%$ to $100 \%(9,10)$. This is significant given that these particular stones had previously failed conventional attempts at extraction and could have undergone more invasive interventions, including open bile duct exploration, for extraction. Our $90 \%$ success rate with EHL for stone fragmentation and subsequent extraction is also consistent with data reported in the literature.

SpyGlass cholangioscopy has certainly proven to be effective in the investigation of biliary strictures and treatment of biliary stones. However, there are certain technical limitations that warrant mention. This is a fibreoptic technology and image quality has been one of the major drawbacks, especially when compared with imaging using 'mother-baby' video cholangioscopes. However, the development of high-definition video technology in the near future is inevitable and will certainly enhance image quality. Nonetheless, given the current constraints with this technology, and that these procedures are time consuming, visualization can be optimized by adequate irrigation and

\section{REFERENCES}

1. Weber A, Schmid RM, Prinz C. Diagnostic approaches for cholangiocarcinoma. World J Gastroenterol 2008;14:4131-6.

2. Ponchon T, Gagnon P, Berger F, et al. Value of endobiliary brush cytology and biopsies for the diagnosis of malignant bile duct stenosis: Results of a prospective study. Gastrointest Endosc 1995; 42:565-72.

3. Howell DA, Parsons WG, Jones MA, Bosco JJ, Hanson BL. Complete tissue sampling of biliary strictures at ERCP using a new device. Gastrointest Endosc 1996;43:498-502.

4. Glasbrenner B, Ardan M, Boeck W, et al. Prospective evaluation of brush cytology of biliary strictures during endoscopic retrograde cholangiopancreatography. Endoscopy 1999;31:712-7.

5. Siddiqui AA, Mehendiratta V, Jackson W et al. Identification of cholangiocarcinoma by using the Spyglass Spyscope system for peroral cholangioscopy and biopsy collection. Clin Gastroenterol Hepatol 2012;10:466-71.

6. Kozarek R, Kodama T, Tatsumi Y. Direct cholangioscopy and pancreatoscopy. Gastrointest Endosc Clin N Am 2003;13:593-607.

7. Chen YK, Pleskow DK. SpyGlass single-operator peroral cholangiopancreatoscopy system for the diagnosis and therapy of bile-duct disorders: A clinical feasibility study (with video). Gastrointest Endosc 2007;65:832-41.

8. Ramchandani M, Reddy DN, Gupta R, et al. Role of single-operator peroral cholangioscopy in the diagnosis of indeterminate biliary proper drainage and suctioning through a generous sphincterotomy. This, however, can sometimes be difficult proximal to a stricture. In our experience, free irrigation can be performed provided suctioning is performed by the assisting nurse with a syringe attached to the operating channel of the SpyScope access catheter. This can eliminate debris and improve image quality.

We also believe that the distal bile duct is the most technically challenging area to visualize. This likely occurs because the tip of the SpyScope access catheter and, hence, the SpyGlass probe, abuts the wall of the bile duct as it straightens coming through the distal bile duct. Some investigators recommend examining the distal bile duct in a 'long' ERCP position so as to align the access catheter with the long axis of the bile duct and position it in the middle of the lumen.

Our study was not a prospective controlled analysis but rather an observational study in which we assessed data from each consecutive patient who underwent SpyGlass cholangioscopy. This design is bound to introduce potential bias in making a visual diagnosis if the clinical history and investigations are known to the endoscopist. This bias could be excluded if the endoscopist performing the procedure is blinded to clinical information. However, because this was an observational study involving a new technical procedure, we believed that the endoscopist should have as much clinical information available as possible to maximize the diagnostic and therapeuitc yield of SpyGlass cholangioscopy.

\section{CONCLUSION}

SpyGlass cholangioscopy is a significant advance in the direct evaluation of the biliary tree and allows for a single endoscopist to directly visualize and biopsy strictures for tissue diagnosis, and perform EHL fragmentation of stones that are otherwise refractory to conventional modalities of extraction such as balloon/basket extraction, mechanical lithotripsy and dilation-assisted balloon extraction. It is a time-consuming - albeit safe - procedure and efficacy is bound to improve with increases in operator experience and improvements in technology, especially those targeting optical optimization.

DISCLOSURES: Dr Gurpal Sandha is a consultant for Boston Scientific. The other authors have no finacial disclosures or conflict of interest relevant to this article. This study was presented, in part, as an abstract at Canadian Digestive Diseases Week, February 23 to 27, 2012, Montreal, Quebec.

lesions: A single-center, prospective study. Gastrointest Endosc 2011;74:511-9.

9. Chen YK, Parsi MA, Binmoeller KF, et al. Single-operator cholangioscopy in patients requiring evaluation of bile duct disease or therapy of biliary stones (with videos). Gastrointest Endosc 2011;74:805-14.

10. Draganov PV, Lin T, Chauhan S, et al. Prospective evaluation of the clinical utility of ERCP-guided cholangiopancreatoscopy with a new direct visualization system. Gastrointest Endosc 2011;73:971-9.

11. Kalaitzakis E, Webster GJ, Oppong KW, et al. Diagnostic and therapeutic utility of single-operator peroral cholangioscopy for indeterminate biliary lesions and bile duct stones. Eur J Gastroenterol Hepatol 2012;24:656-64.

12. Röcsh T, Hofrichter K, Frimberger E, et al. ERCP or EUS for tissue diagnosis of biliary strictures? A prospective comparative study. Gastrointest Endosc 2004;60:390-6.

13. Byrne MF, Gerke H, Mitchell RM, et al. Yield of endoscopic ultrasound-guided fine-needle aspiration of bile duct lesions. Endoscopy 2004;36:715-9.

14. Fritscher-Ravens A, Broering DC, Knoefel WT, et al. EUS-guided fine-needle aspiration of suspected hilar cholangiocarcinoma in potentially operable patients with negative brush cytology. Am J Gastroenterol 2004;99:45-51. 


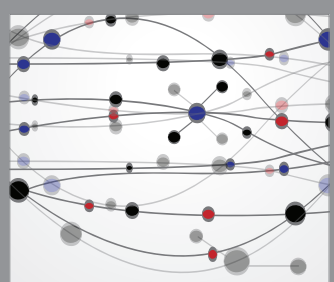

The Scientific World Journal
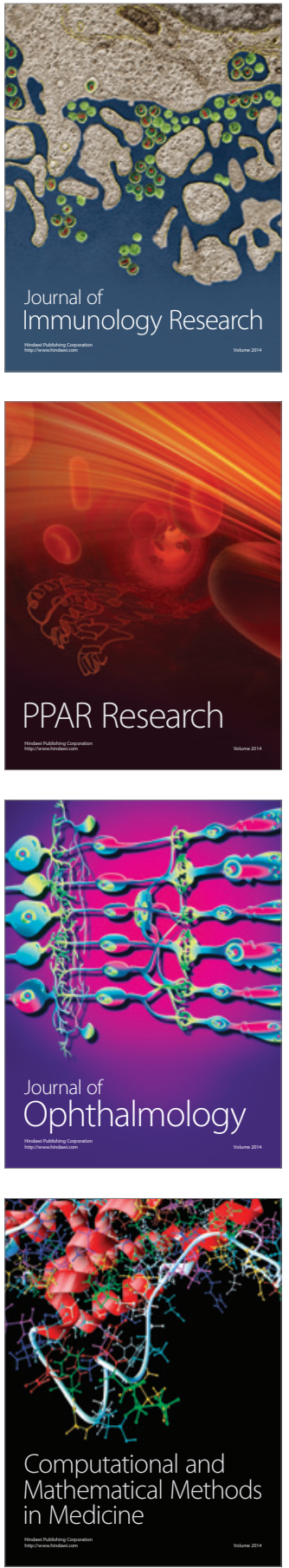

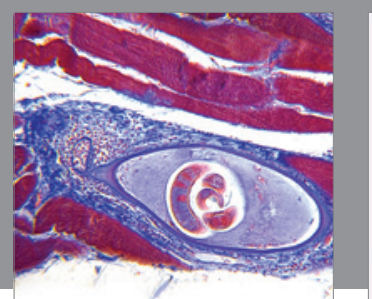

Gastroenterology Research and Practice

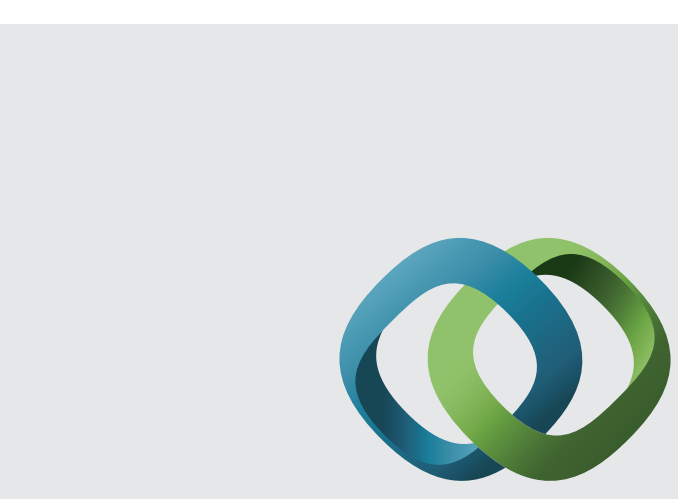

\section{Hindawi}

Submit your manuscripts at

http://www.hindawi.com
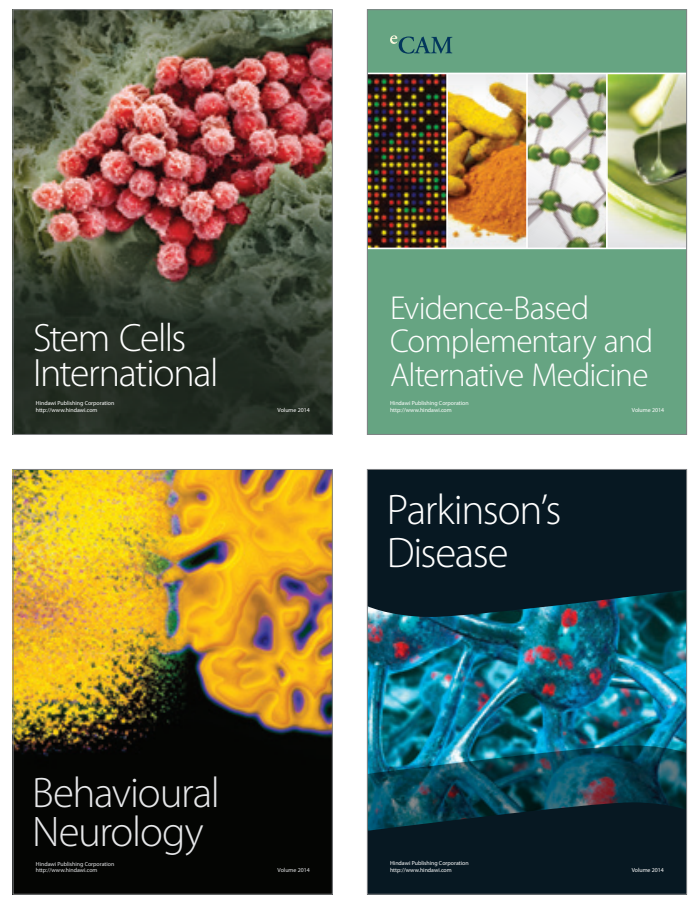
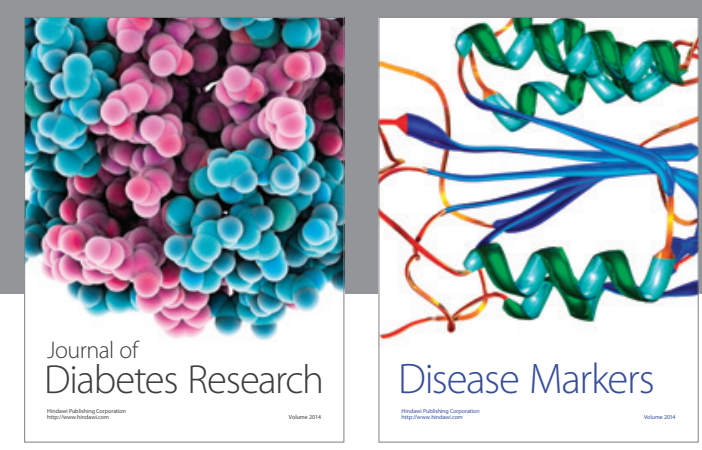

Disease Markers
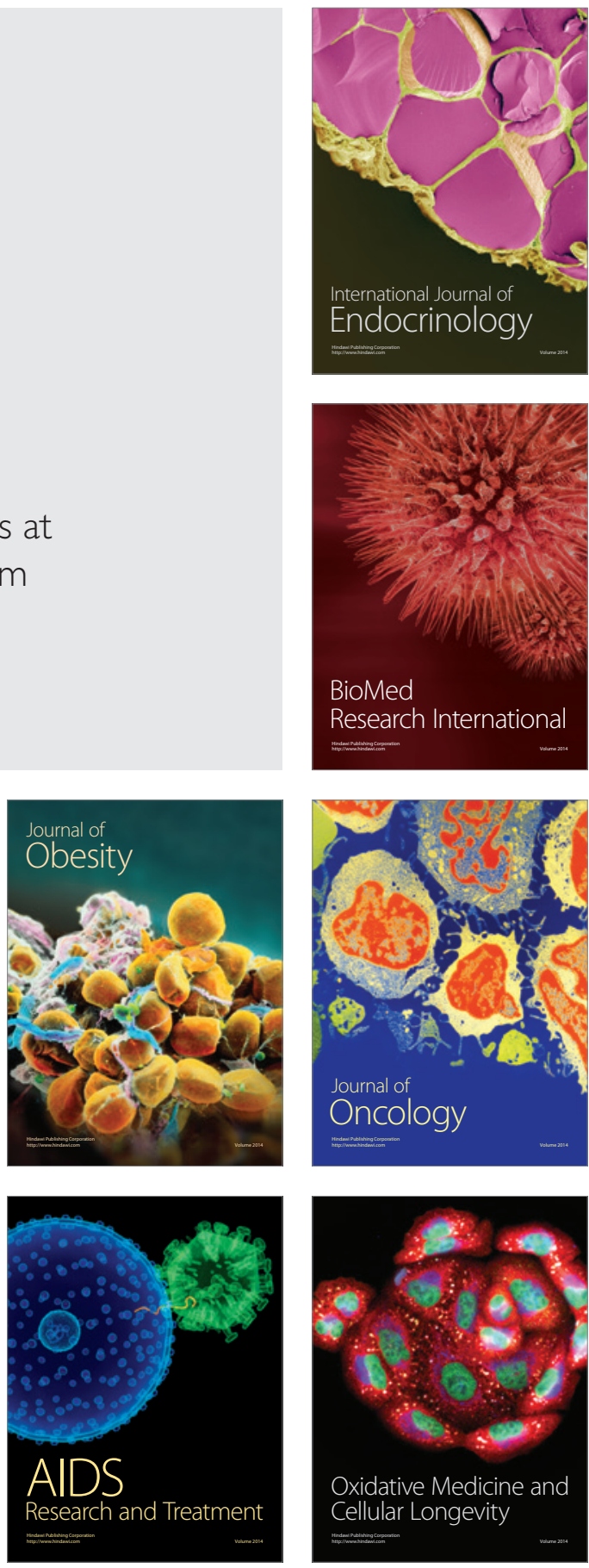